\title{
Lower airway clinical outcome measures for use in primary ciliary dyskinesia research: a scoping review
}

\author{
Florian Gahleitner ${ }^{1,2}$, James Thompson ${ }^{1,3}$, Claire L. Jackson ${ }^{1,3}$, Jana F. Hueppe $\mathbb{C}^{1,3}$, Laura Behan ${ }^{1,3}$, \\ Eleonora Dehlink ${ }^{4}$, Myrofora Goutaki $\mathbb{1}^{5,6}$, Florian Halbeisen $\mathbb{1}^{5,6,7}$, Ana Paula L. Queiroz ${ }^{3}$, \\ Guillaume Thouvenin $\mathbb{1}^{8}$, Claudia E. Kuehni $\mathbb{1}^{5,6}$, Philipp Latzin $\mathbb{\mathbb { D }}^{5,6}$, Jane S. Lucas $\mathbb{1}^{1,3}$ and \\ Bruna Rubbo (1) ${ }^{1,3,9}$
}

${ }^{1}$ Primary Ciliary Dyskinesia Centre, NIHR Biomedical Research Centre, University Hospital Southampton NHS Foundation Trust, Southampton, UK. ${ }^{2}$ Paediatric Respiratory Medicine, Royal Hospital for Children and Young People, Edinburgh, UK. ${ }^{3}$ School of Clinical and Experimental Science, University of Southampton, Faculty of Medicine, Southampton, UK. ${ }^{4}$ Division of Pediatric Pulmonology, Allergy and Endocrinology, Dept of Pediatrics and Adolescent Medicine, Medical University of Vienna, Vienna, Austria. ${ }^{5}$ Institute of Social and Preventive Medicine, University of Bern, Bern, Switzerland. ${ }^{6}$ Paediatric Respiratory Medicine, Children's University Hospital of Bern, University of Bern, Bern, Switzerland. ${ }^{7}$ Basel Institute for Clinical Epidemiology and Biostatistics, Dept of Clinical Research, University Hospital Basel, University of Basel, Basel, Switzerland. ${ }^{8}$ AP-HP, Pneumologic Unit, Trousseau Hospital, Sorbonne Universités, INSERM, Centre de Recherche Saint-Antoine, Paris, France. ${ }^{9}$ School of Health Sciences, University of Southampton, Faculty of Environmental and Life Sciences, Southampton, UK.

Corresponding author: Jane S. Lucas (jlucas1@soton.ac.uk)

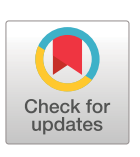

Copyright @The authors 2021

This version is distributed under the terms of the Creative Commons Attribution NonCommercial Licence 4.0. For commercial reproduction rights and permissions contact permissions@ersnet.org

This article has supplementary material available from openres. ersjournals.com

Received: 7 May 2021 Accepted: 31 July 2021

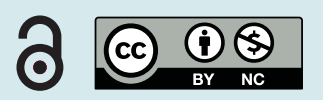

Shareable abstract (@ERSpublications)

Measurement and reporting of lower airway outcome measures in primary ciliary dyskinesia research are not standardised. Validated, disease-specific clinical outcomes are needed to monitor disease progression in future trials and prospective cohorts. https://bit.ly/3yHERQm

Cite this article as: Gahleitner F, Thompson J, Jackson CL, et al. Lower airway clinical outcome measures for use in primary ciliary dyskinesia research: a scoping review. ERJ Open Res 2021; 7: 003202021 [DOI: 10.1183/23120541.00320-2021].

\section{Abstract}

Objectives Disease-specific, well-defined and validated clinical outcome measures are essential in designing research studies. Poorly defined outcome measures hamper pooling of data and comparisons between studies. We aimed to identify and describe pulmonary outcome measures that could be used for follow-up of patients with primary ciliary dyskinesia (PCD).

Methods We conducted a scoping review by systematically searching MEDLINE, Embase and the Cochrane Database of Systematic Reviews online databases for studies published from 1996 to 2020 that included $\geqslant 10$ PCD adult and/or paediatric patients.

Results We included 102 studies (7289 patients). 83 studies reported on spirometry, 11 on body plethysmography, 15 on multiple-breath washout, 36 on high-resolution computed tomography (HRCT), 57 on microbiology and 17 on health-related quality of life. Measurement and reporting of outcomes varied considerably between studies (e.g. different scoring systems for chest HRCT scans). Additionally, definitions of outcome measures varied (e.g. definition of chronic colonisation by respiratory pathogen), impeding direct comparisons of results.

Conclusions This review highlights the need for standardisation of measurements and reporting of outcome measures to enable comparisons between studies. Defining a core set of clinical outcome measures is necessary to ensure reproducibility of results and for use in future trials and prospective cohorts.

\section{Introduction}

Primary ciliary dyskinesia (PCD) is a rare, genetic, multisystem disease that affects motile cilia lining the upper and lower airways, and the eustachian and fallopian tubes [1, 2]. Symptoms start in early infancy, with progressive suppurative lung disease invariably leading to bronchiectasis [3, 4]. Current management of patients with PCD broadly follows that used for patients with cystic fibrosis (CF) and bronchiectasis (formally non-CF bronchiectasis) [5-8]. Therefore, studies have adopted similar outcome measures to 
monitor the natural history and disease progression in PCD, even though PCD has a unique pathophysiology and disease pattern [9].

There is no minimum core set of disease-specific outcome measures in PCD research. This is particularly problematic because the choice of outcome measures informs the selection of data sources from which study information can be collected; the appropriateness, frequency and length of follow-up measurements; and the required number of patients. Appropriate sample size relies on the expected frequency and natural variability of outcomes, and on the effect of interest (or the minimal clinically important difference) [10]. The quality of the knowledge generated by research strongly relies on the selection of appropriate outcomes.

Well-defined and validated disease-specific outcome measures are the most efficient and accurate way to assess new therapies and management options. While true for all diseases, this is particularly poignant for rare diseases, where the number of patients available is limited [11]. An outcome measure that is valid for another disease might not be appropriate to measure the effect of interest, or sensitive enough to detect a subtle effect. For example, spirometry is routinely used to monitor disease progression, but is thought to be an insensitive surrogate marker for early lung disease in CF and, more recently, in PCD [12-15].

The aim of this scoping review was to systematically identify and describe the evidence in this area. In addition, we aimed to highlight the most commonly used pulmonary and related outcomes and to examine the consistency of definitions across studies and the variations on the use and reporting of clinical outcome measures in the PCD literature.

\section{Methodology}

\section{Search strategy}

We followed the a priori scoping review protocol, which is available from the authors upon request. A pilot search included only terms related to the disease (items 1-4 of search terms, supplementary box 1) and one reviewer (BR) scanned the first 1000 abstracts to identify key terms that could be used to build the full search strategy, designed for use in Embase and adapted to MEDLINE. We used Embase subject headings (Emtree) and Medical Subject Headings (MeSH) along with individual terms to develop the search strategy, with limitations applied (supplementary box 1). We used EndNote (version 9.2; Thomas Reuters, Philadelphia, PA, USA) as citation manager.

We performed the search on 2 June 2020. We used a standardised data extraction form developed a priori in Excel, which was piloted on five randomly selected studies and then refined. Data were recorded for the following: publication details (authors, title, year of publication, country and journal), study characteristics (data collection period, study design, countries that contributed with data, inclusion criteria, clinic type, sample size, population characteristics and diagnostic data), and outcome details (outcomes reported, definitions used, correlation between different outcome measures, equipment used and measurement details).

Two reviewers independently assessed titles and abstracts for eligibility. Full text was obtained for all studies deemed relevant by either reviewer or if there was uncertainty on eligibility. Where disagreements remained after full text review, the manuscripts were discussed with a third person. One reviewer manually searched the reference lists of all eligible studies for additional manuscripts. Three reviewers extracted data for a third of the eligible studies each. A fourth reviewer extracted data from $10 \%$ of the total manuscripts included in the study, and their extractions were compared with those extracted by the other three reviewers to ensure consistency.

\section{Inclusion and exclusion criteria}

We included studies describing clinical outcome measures in PCD if they 1) had a study population of $\geqslant 10$ PCD patients, 2) were published in English, 3) were published after 1996 and 4) were conducted on humans. We did not include studies prior to 1996 because the diagnosis of PCD has changed in the past 20 years, therefore older manuscripts may contain a high proportion of patients that would no longer fulfil the current diagnostic criteria [16]. Details of diagnostic data for each of the included studies were recorded (supplementary table 1 ).

We excluded conference abstracts, studies that were not original research and those for which full texts were irretrievable. Studies reporting on multiple disease groups were excluded if the PCD data could not be clearly identified. Manuscripts that reported exclusively on ear, nose and throat symptoms were also excluded. 


\section{TABLE 1 Clinical outcome measures used in studies included in this review, grouped by main outcome measure}

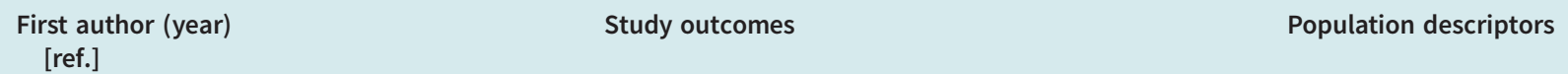

\begin{tabular}{|c|c|c|}
\hline \multicolumn{3}{|c|}{ Spirometry and/or body plethysmography } \\
\hline Davis (2015) [20] & Anthropometry, spirometry, CT & Microbiology \\
\hline DaVIS (2019) [21] & Spirometry, anthropometry, microbiology & None \\
\hline ElLeRMAN (1997) [22] & Spirometry & Chest radiography, microbiology \\
\hline FUGER (2018) [23] & Capillary blood test, spirometry & $\mathrm{CT}$, anthropometry, microbiology \\
\hline GoKDEMIR (2014) [24] & Spirometry, comfort and efficacy, $\mathrm{S}_{\mathrm{pO}_{2}}$ & Anthropometry \\
\hline Halbeisen (2018) [25] & Spirometry & Anthropometry \\
\hline HELLINCKX (1998) [26] & Spirometry, body plethysmography & None \\
\hline Кон (2000) [27] & Spirometry & None \\
\hline LOPES (2015) [28] & Spirometry and body plethysmography, HRCT, dyspnoea & Anthropometry, treatment \\
\hline MAGLIONE (2014) [29] & Anthropometry, spirometry, microbiology & None \\
\hline MARTHIN (2010) [30] & Spirometry & HRCT, chest radiography \\
\hline OLveIRA (2017) [31] & Spirometry, microbiology, treatment, CT & Anthropometry \\
\hline PHILLIPS (1998) [32] & Spirometry & None \\
\hline PIFFERI (2012) [33] & Body plethysmography, HRCT & Microbiology \\
\hline SHAH (2016) [34] & Body plethysmography, HRCT, microbiology & None \\
\hline SUNTHER (2016) [35] & Spirometry & Anthropometry, microbiology, treatment \\
\hline TAMAlet (2001) [36] & Spirometry, blood gas & $\mathrm{CT}$, treatment \\
\hline Vallet (2013) [37] & Spirometry, blood gas, CT & None \\
\hline VIDEBAEK (2019) [38] & Spirometry, microbiology & None \\
\hline \multicolumn{3}{|l|}{ MBW } \\
\hline АнMAD (2015) [39] & MBW & None \\
\hline $\begin{array}{l}\text { AnAgnostopoulou } \\
(2018)[40]\end{array}$ & MBW & Anthropometry \\
\hline GreEN (2012) [41] & $\mathrm{SF}_{6} \mathrm{MBW}$, spirometry & Anthropometry, microbiology \\
\hline GreEN (2016) [42] & MBW, spirometry & Anthropometry \\
\hline IRVING (2013) [43] & Spirometry, MBW, HRCT & Microbiology \\
\hline IRVING (2017) [44] & Spirometry, MBW & None \\
\hline IRVING (2018) [45] & MBW & Spirometry, microbiology \\
\hline $\begin{array}{l}\text { KobBeRNAGEL (2019) } \\
{[46]}\end{array}$ & Spirometry, MBW & Microbiology, anthropometry \\
\hline Kouckí (2020) [47] & MBW, spirometry, endobronchial thickness, bronchoalveolar lavage & Anthropometry, microbiology \\
\hline NYILAS (2017) [48] & MBW/SBW, body plethysmography & Microbiology, treatment \\
\hline NYILAS (2018) [49] & Structural and functional MRI, MBW, spirometry & Anthropometry \\
\hline SмIтH (2018) [50] & MRI, MBW, spirometry & Anthropometry \\
\hline \multicolumn{3}{|l|}{ HRCT } \\
\hline Boon (2015) [12] & Spirometry, $\mathrm{N}_{2} \mathrm{MBW}, \mathrm{HRCT}$ & Anthropometry \\
\hline $\begin{array}{l}\text { COHEN-CYMBERKNoH } \\
\text { (2014) }[51]\end{array}$ & HRCT, spirometry, microbiology & Anthropometry \\
\hline DetTMER (2018) [52] & CT & $\begin{array}{c}\text { Microbiology, spirometry, anthropometry, number } \\
\text { of exacerbations }\end{array}$ \\
\hline HOANG-THI (2018) [53] & Spirometry, CT & Anthropometry \\
\hline JAIN (2007) [54] & Chest radiography, HRCT & Microbiology \\
\hline KENNEDY (2007) [55] & HRCT & Spirometry, microbiology, lobectomy \\
\hline LI (2005) [56] & HRCT & Spirometry, microbiology \\
\hline MAGLIONE (2012) [57] & Spirometry, HRCT & None \\
\hline MAGLIONE (2017) [58] & MRI, CT & $\begin{array}{l}\text { Spirometry, anthropometry, treatment, } \\
\text { microbiology }\end{array}$ \\
\hline MAGNIN (2012) [59] & Spirometry, arterialised capillary blood gases, CT & None \\
\hline MontelLa (2009) [60] & HRCT, MRI, body plethysmography & Microbiology \\
\hline Montella (2009) [61] & HRCT, MRI & None \\
\hline $\begin{array}{l}\text { SANTAMARIA (2008) } \\
\text { [62] }\end{array}$ & HRCT & Spirometry, microbiology \\
\hline TADD (2019) [63] & CT & None \\
\hline \multicolumn{3}{|l|}{ Microbiology } \\
\hline ALANIN (2015) [64] & Microbiology & Spirometry \\
\hline $\begin{array}{l}\text { CoHEN-CYMBERKNOH } \\
\text { (2017) [65] }\end{array}$ & Microbiology, spirometry, CT & Anthropometry \\
\hline Roden (2019) [66] & Microbiology, spirometry & None \\
\hline
\end{tabular}




\begin{tabular}{|c|c|c|}
\hline $\begin{array}{l}\text { First author (year) } \\
\text { [ref.] }\end{array}$ & Study outcomes & Population descriptors \\
\hline RogeRs (2013) [67] & Microbiology & Spirometry \\
\hline \multicolumn{3}{|l|}{ Anthropometry } \\
\hline GoUtAKI (2017) [68] & Anthropometry, spirometry & None \\
\hline SvoBodová (2013) [69] & Anthropometry & None \\
\hline \multicolumn{3}{|l|}{ HRQoL } \\
\hline ALANIN (2017) [70] & HRQoL, microbiology, spirometry, anthropometry & None \\
\hline Behan (2017) [71] & HRQoL & Microbiology, spirometry \\
\hline $\begin{array}{l}\text { CAROTENUTO (2013) } \\
{[72]}\end{array}$ & HRQoL & Anthropometry \\
\hline IOANNOU (2020) [73] & HRQoL & Spirometry \\
\hline $\begin{array}{l}\text { KenIŞ CoşKun (2019) } \\
\text { [74] }\end{array}$ & HRQoL & Spirometry, anthropometry, microbiology \\
\hline MAGLIONE (2014) [75] & HRQoL, spirometry, exercise testing & Exacerbations, microbiology \\
\hline McManus (2003) [76] & HRQoL & Treatment \\
\hline McManus (2006) [77] & HRQoL & None \\
\hline PIFFERI (2010) [78] & HRQoL & Treatment \\
\hline $\begin{array}{l}\text { Valero-Moreno }(2020) \\
{[79]}\end{array}$ & HRQoL & Spirometry \\
\hline WhALLEY (2006) [80] & HRQoL & None \\
\hline $\begin{array}{l}\text { Zengin AkKus (2019) } \\
{[81]}\end{array}$ & HRQoL, sleep & None \\
\hline \multicolumn{3}{|l|}{ Sleep disorder } \\
\hline $\begin{array}{l}\text { COHEN-CYMBERKNOH } \\
(2019)[82]\end{array}$ & Sleep questionnaires, HRQoL & Spirometry \\
\hline OКтем (2013) [83] & $\begin{array}{l}\text { Body plethysmography, sleep questionnaire, PSQI, polysomnography, } \\
\text { HRCT }\end{array}$ & Anthropometry \\
\hline $\begin{array}{l}\text { SANTAMARIA (2014) } \\
{[84]}\end{array}$ & Respiratory polysomnography, sleep questionnaire, HRCT & $\begin{array}{l}\text { Spirometry, anthropometry, treatment, } \\
\text { microbiology }\end{array}$ \\
\hline ŞIŞMANLAR (2018) [85] & Sleep, attention deficit & Spirometry, radiography \\
\hline \multicolumn{3}{|l|}{$\begin{array}{l}\text { Inflammatory } \\
\text { markers }\end{array}$} \\
\hline BusH (2006) [86] & Inflammatory markers, sputum biophysical and transport properties & Spirometry, microbiology \\
\hline Соскx (2017) [87] & Inflammatory markers & Spirometry, microbiology \\
\hline Cockx (2017) [88] & Inflammatory markers & Spirometry, microbiology \\
\hline PAfF (2017) [89] & $\begin{array}{l}\text { HRQoL, LRTI-VAS, exacerbations, inflammatory markers in blood, } \\
\text { inflammatory markers in sputum, spirometry, adverse events, } \\
\text { adherence }\end{array}$ & $\begin{array}{c}\text { Anthropometry, MRC dyspnoea scale score, HRCT } \\
\text { or chest radiography }\end{array}$ \\
\hline RATJEN (2016) [90] & Inflammatory markers from sputum, spirometry, microbiology & None \\
\hline ZIHLIF (2006) [91] & Inflammatory markers from exhaled breath condensate and sputum & Spirometry \\
\hline \multicolumn{3}{|l|}{ Exacerbations } \\
\hline $\begin{array}{l}\text { KobBERNAGEL }(2020) \\
{[92]}\end{array}$ & $\begin{array}{c}\text { Number of exacerbations, spirometry, body plethysmography, MBW, } \\
\text { HRQoL, inflammatory markers, microbiology }\end{array}$ & $\begin{array}{l}\text { Pulse oximetry saturation, respiratory rates, } \\
\text { anthropometry }\end{array}$ \\
\hline PIATTI (2020) [93] & Number of exacerbations, CT, spirometry, microbiology & Anthropometry \\
\hline \multicolumn{3}{|l|}{ Exercise testing } \\
\hline LоOMBA (2017) [94] & Spirometry, exercise testing & None \\
\hline MAdSen (2013) [95] & $\mathrm{N}_{2} \mathrm{MBW}$, spirometry, body plethysmography, exercise testing, HRQoL & Anthropometry, microbiology \\
\hline RING (2018) [96] & Exercise testing, spirometry & Anthropometry, microbiology \\
\hline SIMSEK (2018) [97] & Spirometry, exercise testing, physical activity level & Anthropometry \\
\hline VALERIO (2012) [98] & Spirometry, exercise testing, physical activity assessment & Anthropometry \\
\hline WeLLS (2011) [99] & Exercise testing & $\begin{array}{l}\text { Spirometry, anthropometry, Habitual Activity } \\
\text { Estimation Scale questionnaire }\end{array}$ \\
\hline \multicolumn{3}{|l|}{ Others } \\
\hline JoENSEN (2014) [100] & Breath profiles, microbiology, number of exacerbations & Spirometry \\
\hline KaWAKAMI (1996) [101] & Chronic sputum production, sputum and nasal scores & Fertility \\
\hline KENNEDY (2007) [102] & Lithoptysis, radiographic findings & Spirometry, microbiology, lobectomy \\
\hline MARINO (2019) [103] & Nutrition, spirometry, anthropometry, inflammatory markers & None \\
\hline \multirow[t]{2}{*}{ MIRRA (2015) [104] } & $\begin{array}{c}\text { Vitamin D, body plethysmography, HRQoL, physical activity } \\
\text { assessment, microbiology }\end{array}$ & Anthropometry, HRCT, treatment \\
\hline & Breath profiles & \\
\hline
\end{tabular}




\begin{tabular}{|c|c|c|}
\hline $\begin{array}{l}\text { First author (year) } \\
\text { [ref.] }\end{array}$ & Study outcomes & Population descriptors \\
\hline $\begin{array}{l}\text { MONTUSCHI (2014) } \\
{[105]}\end{array}$ & & $\begin{array}{c}\text { Spirometry, microbiology, anthropometry, } \\
\text { treatment }\end{array}$ \\
\hline Noone (1999) [106] & Clearance during cough, sputum production rate & Spirometry, cough questionnaire \\
\hline PAFF (2013) [107] & Exhaled breath profile & Spirometry, microbiology, pulmonary exacerbations \\
\hline PIFFERI (2017) [108] & $\begin{array}{c}\text { Spirometry, HRCT, body plethysmography, microbiology, extracellular } \\
\text { matrix }\end{array}$ & None \\
\hline $\begin{array}{l}\text { SHOEMARK (2009) } \\
{[109]}\end{array}$ & $F_{\mathrm{eNO}}$ & $\begin{array}{l}\text { Anthropometry, spirometry, treatment, } \\
\text { microbiology, nasal NO }\end{array}$ \\
\hline SMIT (1996) [110] & Lung resection, symptoms questionnaire & Spirometry, bronchiectasis, dyspnoea index \\
\hline ZiHLIF (2005) [111] & Cough frequency, cough symptom score & $\begin{array}{c}\text { Spirometry, eNO, inflammatory markers, } \\
\text { microbiology }\end{array}$ \\
\hline \multicolumn{3}{|l|}{$\begin{array}{l}\text { No main study } \\
\text { outcome }\end{array}$} \\
\hline AвIтBUL (2016) [112] & None & $\mathrm{CT}$, fertility, microbiology, spirometry \\
\hline Boon (2014) [113] & None & $\begin{array}{c}\text { Anthropometry, spirometry, microbiology, chest } \\
\text { radiographs and CT }\end{array}$ \\
\hline EdEN (2019) [114] & None & Spirometry, microbiology, number of exacerbations \\
\hline $\begin{array}{l}\text { EMIRALIOĞLU (2020) } \\
{[115]}\end{array}$ & None & $\begin{array}{l}\text { Spirometry, anthropometry, microbiology, } \\
\text { lobectomy, CT }\end{array}$ \\
\hline $\begin{array}{l}\text { FRIJA-MASSON (2017) } \\
{[116]}\end{array}$ & None & $\begin{array}{l}\text { Spirometry, microbiology, HRCT, dyspnoea score, } \\
\text { treatment, fertility, lobectomy, mortality }\end{array}$ \\
\hline KNOWLES (2014) [117] & None & Spirometry, fertility \\
\hline NoOne (2004) [118] & None & Spirometry, microbiology, radiographs, cough \\
\hline PIFfERI (2015) [119] & None & Spirometry, HRCT, microbiology \\
\hline $\begin{array}{l}\text { YiALLOUROS (2015) } \\
{[120]}\end{array}$ & None & $\begin{array}{c}\mathrm{CT} \text {, microbiology, spirometry, anthropometry, } \\
\text { lobectomy }\end{array}$ \\
\hline \multicolumn{3}{|c|}{$\begin{array}{l}\text { MBW: multiple-breath washout; HRCT: high-resolution computed tomography, HRQoL: health-related quality of life; CT: computed tomography; } \\
\mathrm{S}_{\mathrm{pO}_{2}} \text { : peripheral oxygen saturation; } \mathrm{SF}_{6} \text { : sulfur hexafluoride; SBW: single-breath washout; MRI: magnetic resonance imaging; } \mathrm{N}_{2} \text { : nitrogen; PSQI: } \\
\text { Pittsburgh Sleep Quality Index; LRTI: lower respiratory tract infection; VAS: visual analogue scale; MRC: Medical Research Council; } F_{\text {eNo: }} \text { exhaled } \\
\text { nitric oxide fraction; NO: nitric oxide; eNO: exhaled nitric oxide. }\end{array}$} \\
\hline
\end{tabular}

Definition of outcome measures and classification into subgroups

Outcome measures were defined as any clinical measure used to monitor patients over time or as a marker of disease severity. Outcome measures were classified as 1) study outcomes, defined a priori as study outcome measures; or 2) study population descriptors. The latter indicates measures that were used to characterise the study population (e.g. baseline measures of forced expiratory volume in $1 \mathrm{~s}\left(\mathrm{FEV}_{1}\right)$ ) and those that could potentially be used in future studies (e.g. cough frequency). The supplementary tables contain detailed information on study characteristics and definitions of outcome measures for all studies included in this review.

\section{Statistical analysis}

Critical appraisal of individual studies was not conducted because our focus was on the variety of outcomes used and how these were measured and reported, and not on disease progression, prognosis or treatment effects $[17,18]$. Information about scoping reviews is outlined in the supplementary files.

Descriptive and summary data were analysed in $\mathrm{R}$ statistical package (version 3.2.3; www.r-project.org). Continuous variables were reported as median and interquartile range (IQR). Categorical variables were reported as proportions. Results were reported according to the Preferred Reporting Items for Systematic Reviews and Meta-Analysis Extension for Scoping Reviews checklist [19]. Figures were plotted in R and Tableau 2019 v4.0. manuscripts were reviewed in full, of which 102 met the inclusion criteria and were therefore included (supplementary figure 1) [12, 20-120]. 


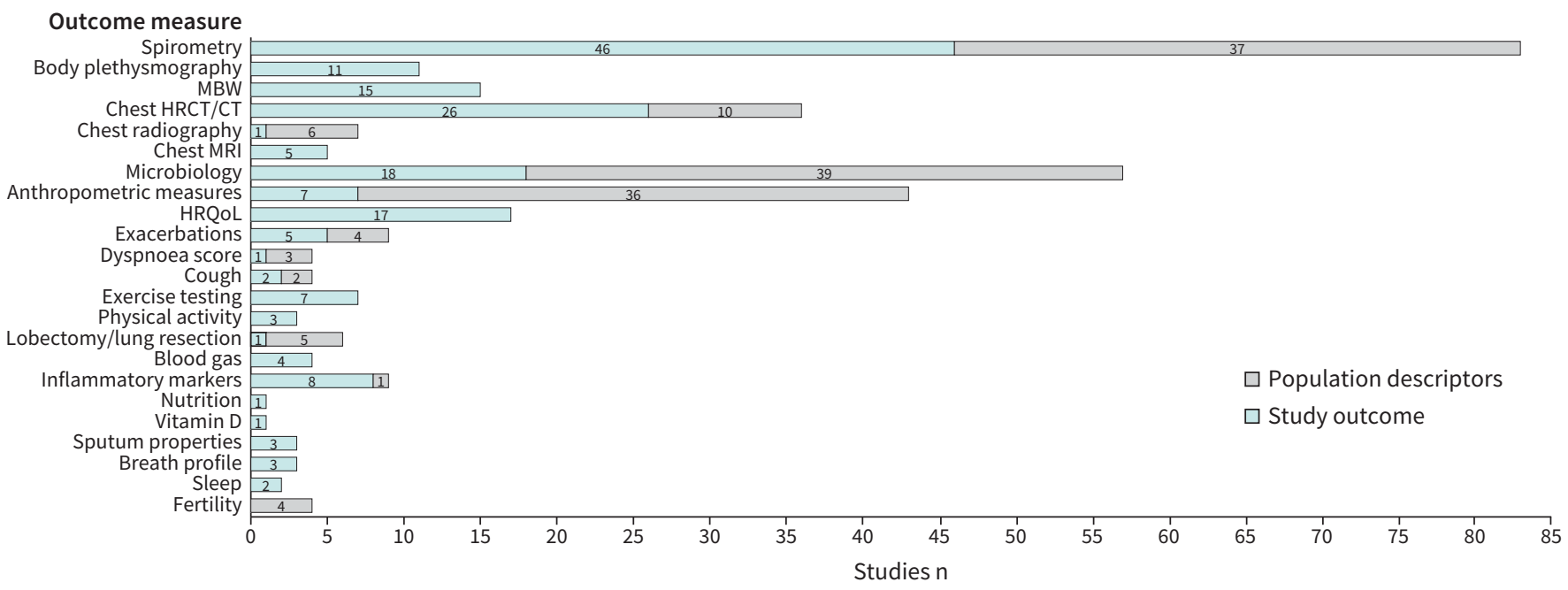

FIGURE 1 Number of studies that reported outcome measures in primary ciliary dyskinesia as either study outcome or population descriptor. Studies often reported on more than one outcome measure and might therefore be featured in more than one instance. MBW: multiple-breath washout; HRCT: high-resolution computed tomography; CT: computed tomography; MRI: magnetic resonance imaging; HRQoL: health-related quality of life.

\section{Study characteristics}

The manuscripts included information on 7289 patients with PCD, with a median of 32 PCD patients per manuscript (IQR 20-62, range 10-1609; supplementary table 1). However, some patients were described in several studies and were included more than once if the studies described different outcome measures.

Manuscripts contained data collected from 23 different countries, but most (89\%) presented single-centre data. Publications with a higher number of PCD patients were from multicentre studies, with the two largest studies containing data derived from a large international PCD cohort study [121].

\section{Outcome measures reported}

93 studies reported on a total of 23 main study outcomes (table 1, figure 1), with 19 presenting data exclusively on population descriptors. 67 presented both study outcomes and population descriptors (table 1 , supplementary table 2).

Spirometry-derived parameters were the most frequently reported clinical outcome measures, followed by chest high-resolution computed tomography (HRCT). Microbiology and anthropometric measures were more often reported as descriptors than as study outcomes (figure 1).

\section{Standardised definitions}

Definitions of outcome measures varied considerably between studies (supplementary table 2). Of 18 studies reporting on microbiology as study outcomes, 14 provided data on chronic colonisation by potentially pathogenic bacteria [29, 31, 34, 38, 59, 64, 65, 70, 75, 82, 96, 100]. The terms chronic colonisation and chronic infection were sometimes used interchangeably, and the classification used to define them varied. Four studies used the Leeds CF criteria (or a modified version) [38, 64, 65, 70]; two used the European consensus for antibiotic therapy against Pseudomonas aeruginosa in CF [75, 104]; and one used the Copenhagen criteria [100]. The remaining studies developed a study-specific criterion, such as pathogen cultured in $\geqslant 50 \%$ of samples from the past year [46, 47] or isolation of the same pathogen on at least two occasions, $\geqslant 3$ months apart in a 1-year period [93].

Sampling frequency of sputum and other microbiological specimens varied between studies. Some studies did not record whether patients had a pulmonary exacerbation at the time of sampling. These differences are likely to have biased results, particularly when reporting prevalence of different respiratory pathogens.

Details on the definitions of all clinical outcome measures reported as study outcomes or population descriptors are provided in supplementary table 2. In the next sections, we focus on the most frequently reported outcome measures. 


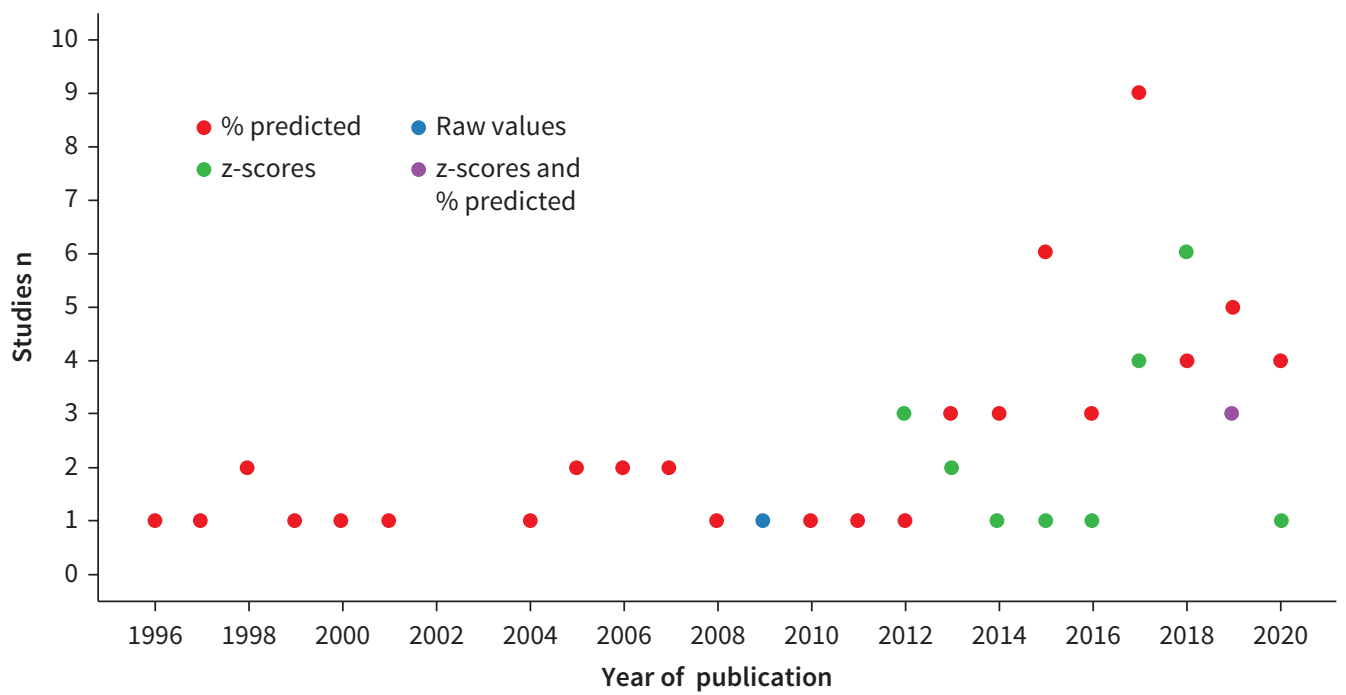

FIGURE 2 Number of studies that reported forced expiratory volume in $1 \mathrm{~s}$ as study outcomes or population descriptors $(n=83)$. Circles are coloured according to the spirometric indices presented in the studies.

\section{Lung function}

\section{Spirometry}

Of the 83 studies reporting spirometry data, 42 reported adherence to European Respiratory Society/ American Thoracic Society guidelines [122] (supplementary table 2). 25 reported on FEV 1 Z-scores; 18 as a study outcome. $\mathrm{FEV}_{1} \%$ predicted was used as an outcome as often as a descriptor (32 versus 31). Studies reporting on $\mathrm{FEV}_{1}$ z-scores were published more recently (figure 2). 14 studies reported calculating z-scores based on the Global Lung Function Initiative (GLI) reference equations [123], two used national references and eight used other equations, while the remainder did not detail the equation used (supplementary table 2).

Five studies compared $\mathrm{FEV}_{1}$ before and after the use of bronchodilators. Studies used inhaled salbutamol [32, 119] or albuterol [28] to assess reversibility and one study performed methacholine challenge before and after the use of salbutamol and placebo [27]. One study did not report which bronchodilator was used [114].

\section{Body plethysmography}

11 studies reported on body plethysmography parameters as study outcomes (table 1, supplementary table 2). Lung residual volume \% predicted was reported by all studies; total lung capacity \% predicted was reported in four studies; and the remaining 19 parameters were rarely reported. Three of these studies additionally measured forced vital capacity (FVC) and $\mathrm{FEV}_{1}$ using plethysmography devices.

\section{Multiple-breath washout}

15 studies reported on parameters derived from the multiple-breath washout (MBW) test as study outcomes (table 1, supplementary table 2), of which $47 \%$ were published in the past 2 years. Lung clearance index (LCI) was most frequently reported. Eight studies presented z-scores for LCI, and five presented values for $\mathrm{S}_{\text {cond }}$ and $\mathrm{S}_{\text {acin }} \mathrm{Z}$-scores (representatives of ventilation inhomogeneity in small conducting and acinar airways, respectively). Studies used different inert tracer gases and equipment; nine of them used nitrogen $\left(\mathrm{N}_{2}\right)$, five used $0.2 \%$ sulfur hexafluoride and the other study did not report which tracer gas was used.

\section{Chest imaging}

40 manuscripts reported on radiological findings, with 26 presenting them as study outcomes and 14 as population descriptors (table 1, supplementary table 2). Of the latter, five studies had spirometry measures as outcomes and provided information on presence or absence of bronchiectasis, diagnosed through chest HRCT/CT or radiography. One study mentioned chest radiography to determine the presence of bronchiectasis; however, the main outcomes were sleep activity and attention deficit scales [85]. The remaining studies did not report on specific outcomes, with data on descriptors only including spirometry, microbiology, anthropometric measurements and fertility. 
Four studies reported on both chest radiography and HRCT and two studies on both chest HRCT and magnetic resonance imaging (MRI).

\section{Radiography}

Bronchiectasis, seen on chest radiography, was used in one study as study outcome and in six as population descriptor (table 1, supplementary table 2). Similar to other imaging modalities, there are no PCD-specific radiography scoring systems, so studies used different scales to report findings. For example, JAIN et al. [54] used a modified version of the Chrispin-Norman score, which was developed for CF [124], while KENNEDy et al. [55] developed a study-specific score for bronchiectasis severity.

\section{HRCT}

Chest HRCT and/or CT was used as study outcome in 25 studies, with an additional 10 studies reporting it as population descriptor (figure 1, table 1, supplementary table 2). Studies adopted modified versions of different scoring scales as there are no PCD-specific scoring systems available. Seven studies used modifications of the Brody score [125], six used the Bhalla score [126], another four applied the Helbich score [127] and a further six used other systems. Of the latter, four used a study-specific score, one by combining the Brody and Bhalla scores [59]. Two studies did not provide any detail on the scoring system used $[37,56]$ and therefore were not included in figure 3.

The use of different measurement scales resulted in inconsistent reporting of subscores (figure 3). For example, extent of bronchiectasis was measured by 1) number of bronchopulmonary segments affected; 2) percentage of each lobe involved; 3) scores from 0 to 3; 4) percentage of central lung and peripheral lung involvement; or 5) size of largest and average bronchopulmonary segment involved. Mucus plugging was measured as size of plug (i.e. small, large), location of plug (Brody score: largest airways, small airways, peripheral lung, central lung; or Helbich score: number of segments) or a mucus classification score (Bhalla score).

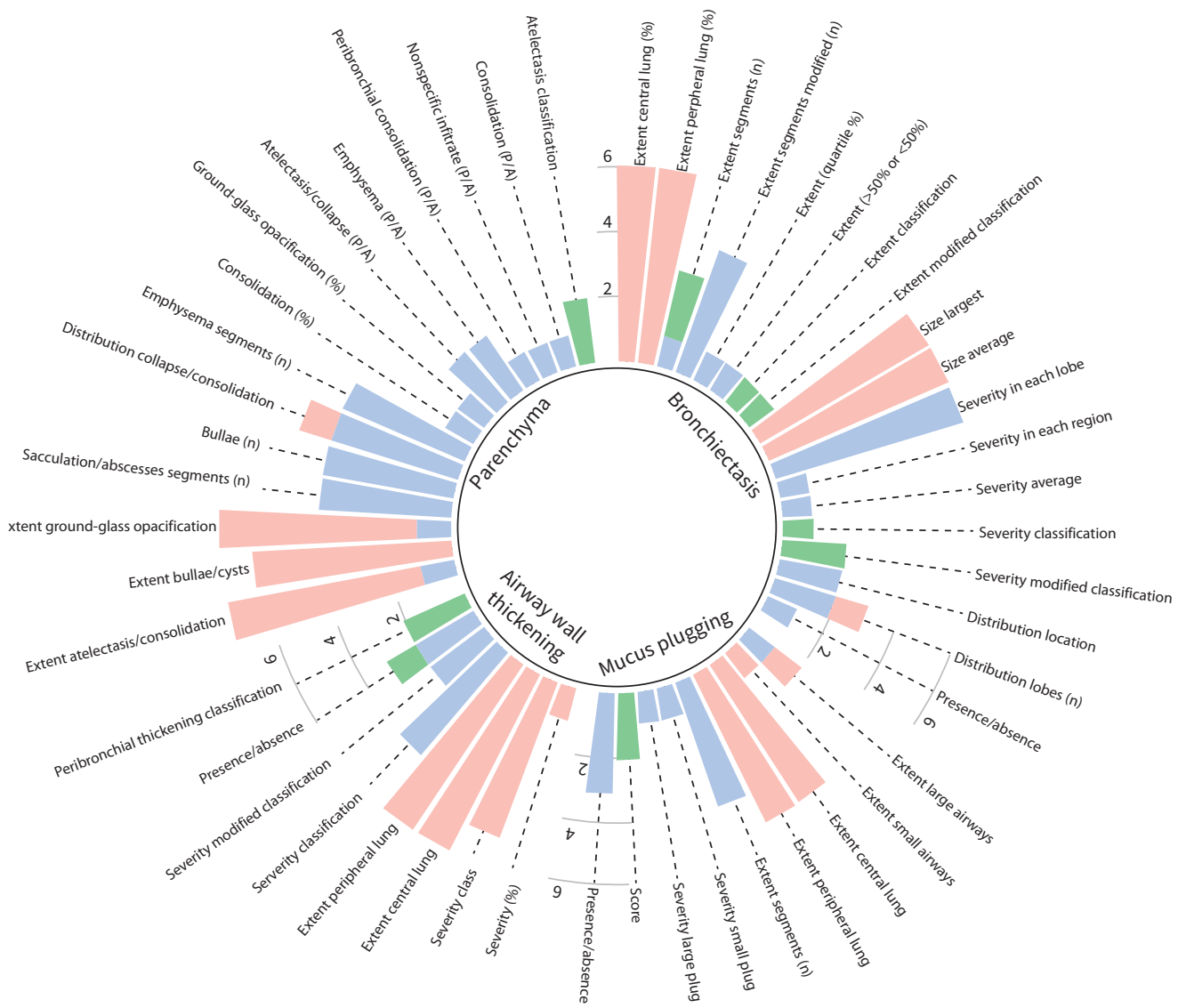

FIGURE 3 High-resolution computed tomography (HRCT) and computed tomography (CT) outcome measures from 23 studies that reported on HRCT/CT scans as study outcomes and had sufficient data on scoring system adopted. Stacked bars represent the number of studies that reported on each subscore component. P: present; A: absent. 
As illustrated in figure 3, not all studies using the Brody score reported on the same subscore components, probably due to study-specific modifications. For example, one study [12] classified the location of the mucus plug as small or large airways, while five other studies used number of central and peripheral lobes involved. In another study that used a modified combination of the Brody and Bhalla scores, the partition of lungs into different segments followed a regional approach as opposed to the commonly used pulmonary segmentation approach in order to expedite the time needed for scoring each scan in routine clinical practice [59].

Unsurprisingly, all 23 studies that presented information on their scoring system reported on bronchiectasis. Studies classified bronchiectasis as mild for those with airway diameter slightly greater than the diameter of adjacent blood vessel, moderate for airway lumen two or three times the diameter of the vessel and severe for those at least three times the diameter of the vessel. However, the extent of bronchiectasis varied, with some reporting the number of bronchopulmonary segments, while others reported percentage of compromised area (figure 3). The second most common features described were airway wall thickening and mucus plugging $(n=19)$.

Two studies comparing CT scores in PCD and CF patients found no differences in the global Brody score. A third study used a study-specific system to analyse CT scans from patients with PCD and CF and then assess results against the Brody and Bhalla scores [63]. They found that bronchial wall thickening, bronchiectasis, mucus plugging, atelectasis and air trapping, features commonly seen in CF patients, were even more common in patients with PCD.

MAGLione et al. [57] reported a significantly higher subscore for severity of collapse or consolidation in PCD compared to CF, and Conen-СyмвеRкNoн et al. [82] found that the lower and middle lobes were more frequently affected in PCD compared to the typical upper lobes compromise seen in CF [34, 55, 62, 82]. TADD et al. [63] reported a higher frequency of extensive tree-in-bud pattern of mucus plugging, bronchocoeles or nodules, thickening of interlobar and intralobular septa, and atelectasis or collapse of the whole lobes in PCD; these are uncommon in CF patients.

Magnetic resonance imaging

Only five studies reported on chest MRI as study outcome (table 1, supplementary table 2). Four studies applied a modified Helbich scoring system, while Sмітн et al. [50] developed a study-specific scoring system for three-dimensional volumetric hyperpolarised MRI. When looking at subscores, MAgLione et al. [75] found no significant difference between total MRI scores and subscores in 20 PCD and 20 mild CF patients, aside from a higher score for severity of collapse/consolidation in PCD patients. In a smaller study of 11 PCD children, all presented with mostly small and heterogeneous abnormalities on ventilation MRI [50].

\section{Microbiology}

57 studies reported on microbiology; 18 as study outcomes and 39 as population descriptors (table 1, supplementary table 2). Studies reported most commonly on Haemophilus influenzae and P. aeruginosa, followed by Staphylococcus aureus. Some studies distinguished between mucoid and nonmucoid strains of $P$. aeruginosa, while others simply reported on P. aeruginosa infection. Similarly, S. aureus subtypes were inconsistently stratified across studies, with some reporting methicillin-sensitive and -resistant strains separately. Not all studies stratified pathogen prevalence by age group (supplementary figure 2).

\section{Other outcome measures}

\section{Health-related quality of life scores}

17 studies reported on health-related quality of life (HRQoL) as study outcomes (table 1). However, only two studies [74, 92] used QOL-PCD, as most were published before the disease-specific tool was validated [71, 128, 129]. The most common instruments adopted were the St George's Respiratory Questionnaire (SGRQ) (eight studies) and the 36-item short form survey (SF-36) (seven studies) (supplementary table 2).

\section{Pulmonary exacerbations}

Nine studies reported on pulmonary exacerbations; five as study outcomes. However, none used the PCD-specific consensus, as the studies included in this review pre-date it [130]. Two randomised controlled trials (RCTs) used pulmonary exacerbation as a primary outcome. PAFF et al. [89] defined an exacerbation as respiratory symptoms that led to initiation of systemic antibiotic treatment irrespective of culture results, or a decline of $\geqslant 10 \%$ in $\mathrm{FEV}_{1} \%$ predicted compared to baseline at screening and randomisation [89], while KobBernagel et al. [92] defined it as worsening of respiratory symptoms leading to initiation of antibiotic treatment in the week prior to the clinical appointment up to the day of the 
appointment. RATJEN et al. [90] studied a subset of patients who experienced an episode of exacerbation, defined as an increase in lower airway symptoms treated with oral antibiotics. JoEnsEn et al. [100] applied a definition developed for CF studies [61] (supplementary table 2). SunTHER et al. [35] only included patients with pulmonary exacerbation, defined as change in respiratory status for which intravenous antibiotics were needed.

\section{Comparison between outcome measures}

Most studies comparing outcome measures used spirometry as the reference to which the other outcomes were compared (figure 1). 12 studies describing imaging modalities reported on agreements or correlations with other outcome measures [12, 33, 43, 49, 53, 55, 57, 60, 93, 108, 119]. The most common comparison was between spirometry-derived $\mathrm{FEV}_{1}$ and HRCT, with studies presenting contradictory findings. Four studies [33, 53, 55, 93] found agreement between the two outcomes, one of which used an automated CT scoring for adults with PCD [53]. Three studies used a modified Bhalla system and the other a study-specific scoring system. The other four studies [43, 57, 62, 119] reported no association.

$\mathrm{FEV}_{1}$ was compared to MBW-derived LCI in eight studies, also with contradictory results. Two studies reported no association [41, 44], while the other six [12, 35, 42, 43, 46, 49] found correlations between some parameters. Both Boon et al. [12] and KobBernagel et al. [46] found a significant negative correlation between $\mathrm{LCI}, \mathrm{FEV}_{1}$ and $\mathrm{FEV}_{1} / \mathrm{FVC}$ ratio z-scores, while IRving et al. [43] only found a correlation between LCI and forced expiratory flow at 25-75\% of FVC ( $\left.\mathrm{FEF}_{25-75}\right)$ z-scores. GREEN et al. [42] did not find any correlation between LCI and FEV 1 z-scores in PCD patients, but reported a significant correlation between $\mathrm{LCI}_{2.5}$ (LCI at 2.5\%, standard LCI) and $\mathrm{FEV}_{1} / \mathrm{FVC}$ ratio and $\mathrm{FEF}_{25-75} \mathrm{z}$-scores.

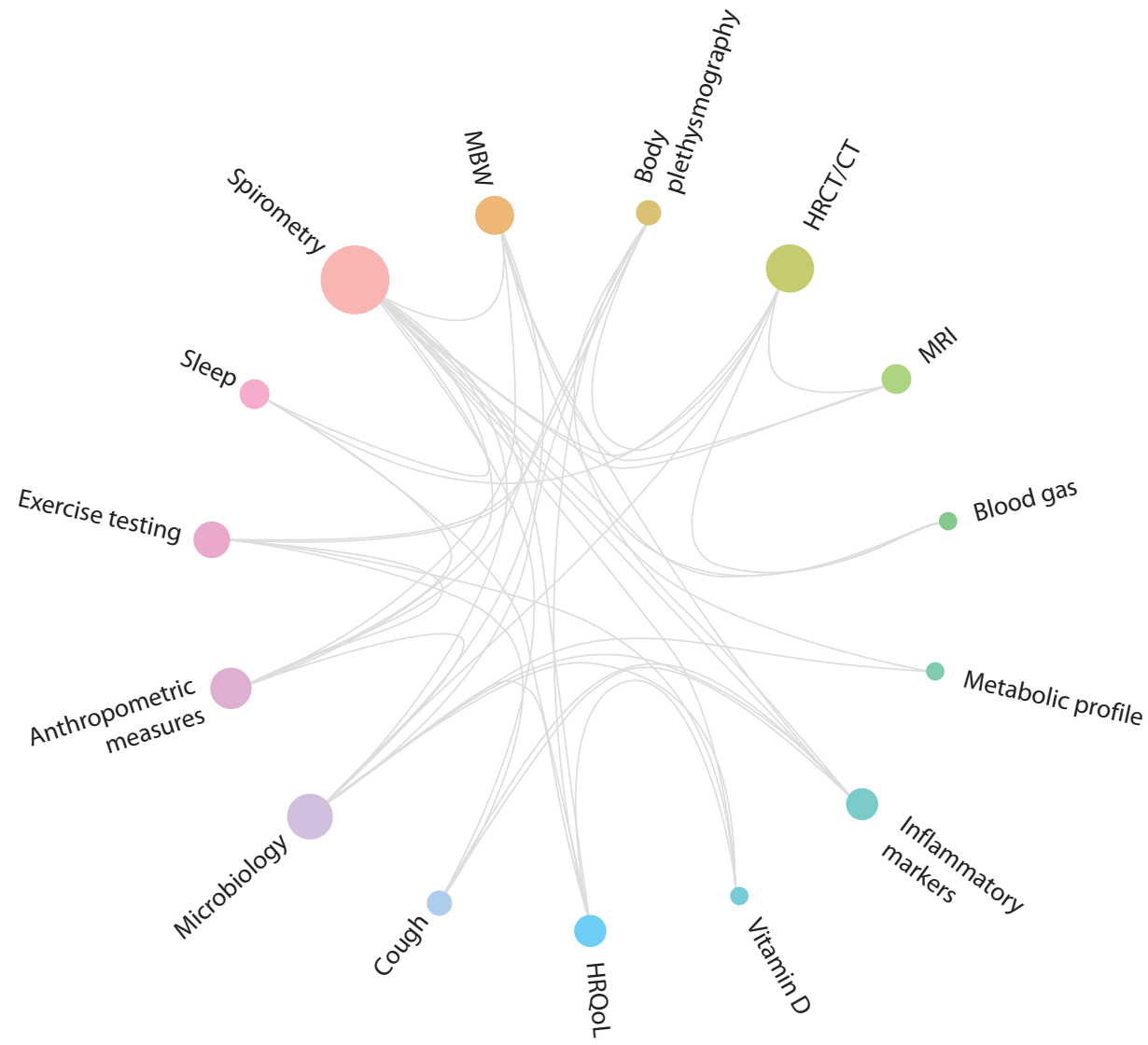

FIGURE 4 Correlations or associations between outcomes measures. Connections between circles depicts the correlated outcomes, with the size of each circle representing the number of studies that reported correlations or associations of that particular outcome. MBW: multiple-breath washout; HRQoL: health-related quality of life; MRI: magnetic resonance imaging; HRCT: high-resolution computed tomography; CT: computed tomography. 
MBW-derived LCI might be more sensitive to detect early or milder disease. NYILAs et al. [49] found that more than half of the patients with abnormal LCI values and MRI scores had normal FEV $_{1}$ z-scores. In another study, five (15\%) patients had abnormal LCI, but normal $\mathrm{FEV}_{1}$ z-scores [43]. In addition, LCI was shown to be more sensitive than $\mathrm{FEV}_{1}$ to detect lung structure abnormalities [12]. Boon et al. [12] reported that LCI z-scores were concordant with total CFCT scores (a variant of the Brody score) in $83 \%$ of the patients, while Kobbernagel et al. [46] and Irving et al. [43] found no correlation.

Studies comparing HRCT to indices derived from body plethysmography, chest MRI and microbiology found significant correlations. However, these were generally limited to subscores (e.g. bronchiectasis on HRCT and body plethysmography and collapse/consolidation on HRCT and MRI) as opposed to the global score.

Other associations between outcome measures are shown in figure 4.

\section{Randomised controlled trials}

Only five of the included studies were RCTs, of which four adopted a crossover design (supplementary table 3).

The efficacy of 6 months azithromycin maintenance therapy in reducing the number of respiratory exacerbations in patients with PCD was assessed in a double-blind, parallel-group placebo-controlled RCT at six European PCD centres [92]. Secondary outcomes included changes in spirometry, body plethysmography, $\mathrm{N}_{2}$ MBW, HRQoL, audiometry, sputum microbiology and inflammatory markers.

The effect of hypertonic saline on HRQoL in PCD adults was investigated in a 28-week double-blind crossover RCT with a washout period of 4 weeks. HRQoL was measured by the SGRQ and Quality of Life Questionnaire - Bronchiectasis [89].

GoKDEMIR et al. [24] assessed spirometry measurements (FEV ${ }_{1}, \mathrm{FVC}$, peak expiratory flow and $\left.\mathrm{FEF}_{25-75}\right)$ in children with PCD using two different airway clearance methods. Half performed conventional pulmonary rehabilitation for 5 days in hospital followed by a 2-day washout period and then high-frequency chest-wall oscillation for another 5 days at home. However, techniques differed between the settings. Another crossover RCT investigated differences in $\mathrm{FEV}_{1} \%$ predicted and in bronchial hyperresponsiveness after the use of salbutamol compared to placebo in children with PCD at both 3 and 6 weeks compared to pre-treatment measurements [27].

Noone et al. [106] reported on mean whole-lung clearance rates of a radionucleotide marker after inhalation of uridine-5'-triphosphate compared to placebo during a series of controlled coughs to induce mucociliary clearance in PCD adolescents and adults.

\section{Discussion}

This scoping review identified 23 clinical outcome measures used in PCD research. We found a high degree of heterogeneity in the definitions of outcome measures.

Spirometry and chest HRCT were most frequently reported as study outcomes. Spirometry is widely available, relatively easy to perform and does not require expensive equipment [122, 123]; however, researchers have questioned its appropriateness as a measure to monitor disease progression in PCD [35, 49, 57]. A meta-analysis found that mean $\mathrm{FEV}_{1}$ ranged from $51 \%$ predicted to $96 \%$ predicted, with high heterogeneity between studies that could not be explained by age or other factors [131]. Studies that did not report on which reference values they used or those that did not provide information on quality control reported lower mean $\mathrm{FEV}_{1}$ values. Clinical status at the time of measurement was rarely reported and therefore could not be included in the meta-regression. The largest study to date investigating lung disease in PCD patients found consistently low $\mathrm{FEV}_{1}$ z-scores in patients with PCD compared to reference data, similar to those seen in CF patients [25].

To our knowledge, no study has investigated the timing of physiotherapy in relation to spirometry, which is a significant limitation as, anecdotally, airway clearance techniques can improve spirometric indices. An ongoing multicentre prospective cohort is investigating variability of lung function in stable PCD patients, adjusting for factors such as timing of inhaled medication and respiratory physiotherapy [132, 133] (https:// clinicaltrials.gov/ct2/show/NCT03704896). Another potential source of variability when using spirometry-derived measurements are the adopted reference equations, as variations between the GLI and national reference equations can occur. Evidence from a longitudinal CF cohort highlighted the disparity 
between reference equations, demonstrating the need for a standardised approach to interpreting spirometric measurements to facilitate appropriate comparisons both within and between centres and countries [134].

Chest HRCT has been proposed as a surrogate outcome measure in the assessment of lung disease. However, there are no validated scoring systems for PCD. All studies included in this review used CF-derived scoring systems [125-127], despite significant pathophysiological differences between the two conditions [9, 135]. Additionally, studies do not report the lung volumes at which the CT scans are obtained, with no details on the standard operating procedures used to record the images.

Location, distribution and frequency of features seen in HRCT scans of patients with PCD differ from those with CF [135]. The weights applied to each feature might not be suitable for PCD as CF-derived scoring systems do not reflect the range and severity of structural changes in PCD. Studies found that extensive tree-in-bud pattern of mucus plugging, bronchocoeles or nodules, thickening of interlobar and interlobular septa and atelectasis mostly seen as collapse of whole lobes were frequently described in PCD, but uncommon in CF [52, 63, 135]. Reporting only the global CT scores might be misleading, as some components of the score might be more relevant to clinical outcome, particularly when using a non-disease-specific score. These findings underscore the need for disease-specific CT scoring systems. HoANG-THi et al. [53] highlighted the fact that visual scores such as the ones routinely used in the assessment of PCD and CF patients can be highly subjective. In response, they developed an automated CT scoring for adults with PCD, which had moderate to good correlation with $\mathrm{FEV}_{1}$ and FVC.

MRI scans of the chest have historically been considered of limited value due to intrinsic characteristics of the pulmonary tissue, and the presence of physiological motion resulting in poor resolution and motion artefacts. Research has focused on improving techniques to obtain better-quality images [136, 137].

Lack of agreement between spirometry, HRCT, MBW and MRI parameters reported by some studies might reflect variations on measurement and reporting of outcomes. Discrepancies could be explained by different scoring systems for HRCT, differences in tracer gas for MBW, variations in measurements, inability of some of the outcome measures to accurately monitor lung disease progression in PCD or true variability between populations (e.g. underlying genetics, differences in disease severity or treatment). Interpretation of findings was limited by the retrospective nature of most studies. In some cases, there was a significant time lag between measurements performed with the methods that were compared [12], or tests were applied to different subpopulations (e.g. HRCT scans conducted only in the older population with more severe lung disease [43] or conducted at different time points of clinical stability [57]). Contradictory results could also be attributed to variations in study design, inclusion criteria or small sample sizes, resulting in variability due to chance.

Recent studies have focused on MBW, with almost half of them published in the past few years. NyILAS et al. [49] found that LCI was not able to distinguish between reversible and irreversible lung damage, despite being more sensitive than spirometry to detect changes. A limitation of LCI is the long washout time, and therefore test duration, which is particularly problematic for patients with compromised lung capacity and young children. Studies looking at shorter washout periods have shown promising results, with $\mathrm{LCI}_{5}$ providing a good alternative to the more conventional $\mathrm{LCI}_{2.5}[39,41,109]$. However, as NyILAS et al. [49] demonstrated, combining different modalities (e.g. MRI and MBW) can be necessary to accurately capture changes in the lungs of PCD patients.

In terms of microbiological outcomes, studies should present a breakdown of pathogens by age group, since the prevalence of bacterial species changes with age $[66,85]$. Studies included in this review were also limited by the lack of a universal panel that could be applied consistently across different centres, particularly when reporting the prevalence of each pathogen isolated. Rogers et al. [67] highlighted that some of dominant genera of bacteria found in the sputum of PCD patients were from those unlikely to be detected without specific growth conditions being present. Variations in the frequency of specimen collection and type of specimen (e.g. expectorated sputum, cough swab, bronchoalveolar lavage) will also probably affect pathogen prevalence.

Small sample sizes were a common limitation in most studies, highlighting the importance of national and international disease registries, large collaborative multicentre studies and standardised definitions that enable pooling of data [121, 138-140]. Few studies included sample-size calculations, hampering the interpretation of statistically insignificant results due to underpowered samples. 
The number of larger multicentre studies has increased in recent years, highlighting the important role of PCD networks such as Better Experimental Screening and Treatment for Primary Ciliary Dyskinesia (BESTCILIA), Better Experimental Approaches to Treat Primary Ciliary Dyskinesia (BEAT-PCD) and the Genetic Disorders of Mucociliary Clearance Consortium in advancing collaborative research in the field [132, 133, 141, 142]. Such collaborations were featured in two studies that used data derived from the international PCD cohort [121].

RCTs and prospective cohort studies with long follow-up periods are uncommon in rare diseases due to the small sample sizes available, high costs and limited commercial interest from pharmaceutical industries $[5,143,144]$. As a result, the majority of PCD studies are cross-sectional case-control studies or small cohort studies with limited follow-up. Interventional studies are currently being designed, but will require close international collaboration and data sharing. The success of these and of future trials will depend on the selection of appropriate outcome measures.

Our review was limited by the quality of the information provided in the studies. As our aim was to identify the evidence available and describe definitions for clinical outcome measures used in PCD research, we opted to conduct a scoping review and therefore we did not critically appraise the studies included in this review. We did not perform quantitative analysis, as studies were heterogeneous, impeding a formal meta-analysis. In fact, the aim of this review was to highlight this heterogeneity. Another limitation was that the broad nature of this review impeded us from focusing on any one clinical outcome measure, and therefore systematic reviews with or without meta-analysis are still needed for the more commonly used and promising outcome measures. A separate review to evaluate upper airways clinical outcome measures is underway, and therefore we deliberately excluded these studies from our scoping review. Despite our attempts not to restrict the search to specific outcomes, our review is limited to the clinical outcomes that were included as search terms.

\section{Recommendations}

We advocate that outcome measures for use in future prospective trials must fulfil the following criteria: 1) measured across different studies in a standardised manner (e.g. using the standardised PCD data collection tool FOLLOW-PCD [145]); 2) used and reported regularly by a sufficient number of studies; 3) use currently recommended definitions (e.g. z-scores based on GLI recommendations); and 4) be embedded within the current knowledge of PCD pathophysiology and natural history (table 2). This will require consensus statements, which are currently being developed by a BEAT-PCD working group.

Spirometry was the outcome most frequently used for disease monitoring, but there were major problems with standardisation on measuring and reporting $\mathrm{FEV}_{1}$. Large studies are needed to investigate the suitability of spirometry-derived parameters as accurate and sensitive surrogate markers.

Chest HRCT might be a good candidate for longitudinal follow-up of lung disease progression in PCD, particularly modalities using low radiation $[146,147]$. However, a disease-specific scoring system must be developed. Agreement between HRCT and other outcomes were limited to subscores as opposed to global score, emphasising the need for PCD-specific scores that consider the distribution, frequency and patterns of lung compromise in this population, and that can be easily applied by clinicians without being unnecessarily time-consuming.

The United States Food and Drug Administration and the European Medicines Agency encourage the inclusion of patient-centred outcome measures. A systematic review on the patient's experience of PCD reported worsening of respiratory symptoms with age, which was also associated with decline in the physical and mental domains [148]. QOL-PCD, a HRQoL instrument, is the only validated disease- and age-specific cross-cultural clinical outcome measure in PCD [71, 128, 129, 149, 150]. QOL-PCD correlated well with the Sino-Nasal Outcome Test (SNOT-20) for upper airway symptoms, the COPD-specific SGRQ for lower airways symptoms and SF-36 for physical functioning, role functioning and mental health [71].

An expert consensus on the definition of pulmonary exacerbations in PCD for children and adults was developed recently [130]. The importance of disease-specific definitions was highlighted by the fact that studies that used exacerbations as an outcome adopted different definitions for pulmonary exacerbations $[35,90,92]$. There is now a need to validate the proposed definition and develop a separate definition for upper airway exacerbations. 


\section{TABLE 2 Summary of clinical outcome measures for use in primary ciliary dyskinesia (PCD) research}
Strengths
Limitations

Future directions

\section{Spirometry \\ Routinely measured Reported in $78 \%$ of studies} included
Unknown accuracy and sensitivity as surrogate marker for lung disease Unstandardised reporting of indices

\begin{tabular}{|c|c|c|}
\hline HRCT & $\begin{array}{l}\text { Can assess structural lung } \\
\text { damage } \\
\text { Reported in } 37 \% \text { of studies } \\
\text { included }\end{array}$ & $\begin{array}{l}\text { Reliance on established CF scoring systems } \\
\text { Frequent high doses of radiation if used routinely for } \\
\text { disease monitoring; however, low-dose radiation } \\
\text { modules are being developed }\end{array}$ \\
\hline HRQoL & $\begin{array}{l}\text { Patient-centred outcome } \\
\text { measure } \\
\text { QOL-PCD was developed } \\
\text { and validated for use in } \\
\text { PCD }\end{array}$ & Lack of a minimal clinically relevant difference \\
\hline
\end{tabular}

Pulmonary exacerbations
Developed for use in PCD

Has not been validated

\section{Conclusions}

This scoping review highlights the variety of outcomes and definitions used in PCD research. It also underscores significant differences in measurement and reporting of outcomes. Validated disease-specific clinical outcome measures are needed to monitor disease progression in PCD in future prospective cohort studies and clinical trials. Appropriate outcomes need to be chosen based on the specific patient groups and the study intervention. New studies should aim to measure and report outcomes using standardised methods to build up the body of evidence needed to meaningfully compare results. New promising outcome measures should also be used, such as MBW-derived LCI and microbiology, to assess and better understand the appropriateness of these for long-term monitoring in PCD.

Acknowledgement: This work was presented in poster discussion session at the ERS International Congress on 29 September 2019.

Provenance: Submitted article, peer reviewed.

Author contributions: B. Rubbo, P. Latzin and J.S. Lucas conceived the review; B. Rubbo, J. Thompson and C.L. Jackson performed the literature search; B. Rubbo, C.L. Jackson, E. Dehlink, P. Latzin and J.S. Lucas discussed and agreed on the inclusion and exclusion criteria; B. Rubbo, F. Gahleitner, J. Thompson and C.L. Jackson screened publications for eligibility; B. Rubbo, F. Gahleitner, J. Thompson, C.L. Jackson and A.P.L. Queiroz extracted the data; B. Rubbo, F. Gahleitner and J.F. Hueppe analysed the data; B. Rubbo and F. Halbeisen plotted the figures; B. Rubbo drafted the manuscript; F. Gahleitner, J. Thompson, C.L. Jackson, L. Behan, E. Dehlink, M. Goutaki, F. Halbeisen, G. Thouvenin, C. Kuehni, P. Latzin and J.S. Lucas critically reviewed the manuscript. All authors reviewed and approved the final manuscript.

Conflict of interest: M. Goutaki and C.E. Kuehni report that the BEAT-PCD COST Action supported their travel to and attendance of meetings during the period 2015-2019. P. Latzin reports personal fees from Vertex, Novartis, Roche, Polyphor, Vifor, Gilead, Schwabe, Zambon and Santhera, and grants from Vertex, outside the submitted work. J.S. Lucas reports that on 2 December 2019 she attended the Rare Lung and Airway Diseases on Childhood meeting at the Primary Ciliary Dyskinesia and Neonatal Interstitial Lung Diseases Conference in Jerusalem, Israel, to deliver an invited lecture on monitoring disease progression in PCD; her local travel and accommodation were arranged by the conference organisers, and her international travel was supported by BEAT-PCD. All other authors have nothing to disclose. 
Support statement: B. Rubbo, J. Thompson, C.L. Jackson, J.F. Hueppe, L. Behan, E. Dehlink, M. Goutaki, F. Halbeisen, G. Thouvenin, C. Kuehni, P. Latzin and J.S. Lucas participate in the Better Evidence to Advance Therapeutic Options for PCD (BEAT-PCD) network (COST action BM 1407 and ERS Clinical Research Collaboration). B. Rubbo received a short-term scientific mission, provided through BEAT-PCD funding, to travel to Switzerland to discuss the review with M. Goutaki, F. Halbeisen and C. Kuehni.

\section{References}

1 Shoemark A, Lucas JS. Diagnosis of primary ciliary dyskinesia: current recommendations and future perspectives. In: Chalmers JD, Polverino E, Aliberti S, eds. Bronchiectasis (ERS Monograph). Sheffield, European Respiratory Society, 2018; pp. 267-281.

2 Lucas JS, Walker WT, Kuehni CE, et al. Primary ciliary dyskinesia. In: Cordier JF, ed. Orphan Lung Diseases (ERS Monograph). Sheffield, European Respiratory Society, 2011; pp. 201-217.

3 Lucas JS, Davis SD, Omran H, et al. Primary ciliary dyskinesia in the genomics age. Lancet Respir Med 2020; 8: 202-216.

$4 \quad$ Goutaki M, Meier AB, Halbeisen FS, et al. Clinical manifestations in primary ciliary dyskinesia: systematic review and meta-analysis. Eur Respir J 2016; 48: 1081-1095.

$5 \quad$ Kuehni CE, Goutaki M, Rubbo B, et al. Management of primary ciliary dyskinesia: current practice and future perspectives. In: Chalmers JD, Polverino E, Aliberti S, eds. Bronchiectasis (ERS Monograph). Sheffield, European Respiratory Society, 2018; pp. 282-299.

6 Lucas JS, Alanin MC, Collins S, et al. Clinical care of children with primary ciliary dyskinesia. Expert Rev Respir Med 2017; 11: 779-790.

7 Barbato A, Frischer T, Kuehni CE, et al. Primary ciliary dyskinesia: a consensus statement on diagnostic and treatment approaches in children. Eur Respir J 2009; 34: 1264-1276.

8 Shapiro AJ, Zariwala MA, Ferkol T, et al. Diagnosis, monitoring, and treatment of primary ciliary dyskinesia: PCD foundation consensus recommendations based on state of the art review. Pediatr Pulmonol 2016; 51: $115-132$.

9 Lucas JS, Carroll M. Primary ciliary dyskinesia and cystic fibrosis: different diseases require different treatment. Chest 2014; 145: 674-676.

10 Valentgas P, Dreyer N, Wu AW. Outcome definition and measurement. In: Valentgas P, Dreyer N, Nourjah P et al., eds. Developing a Protocol for Observational Comparative Effectiveness Research: a User's Guide. Rockville, Agency for Healthcare Research and Quality (US), 2013. Available from: www.ncbi.nlm.nih.gov/ books/NBK126186/

11 Kuehni CE, Goutaki M, Kobbernagel HE. Hypertonic saline in patients with primary ciliary dyskinesia: on the road to evidence-based treatment for a rare lung disease. Eur Respir J 2017; 49: 1602514.

12 Boon M, Vermeulen FL, Gysemans W, et al. Lung structure-function correlation in patients with primary ciliary dyskinesia. Thorax 2015; 70: 339-345.

13 Maglione M, Bush A, Montella S, et al. Progression of lung disease in primary ciliary dyskinesia: is spirometry less accurate than CT? Pediatr Pulmonol 2012; 47: 498-504.

14 Nyilas S, Schlegtendal A, Yammine S, et al. Further evidence for an association between $\mathrm{LCl}_{\text {and }} \mathrm{FEV}_{1}$ in patients with PCD. Thorax 2015; 70: 896.

15 Mayer-Hamblett N, Ramsey BW, Kronmal RA. Advancing outcome measures for the new era of drug development in cystic fibrosis. Proc Am Thorac Soc 2007; 4: 370-377.

16 Lucas JS, Barbato A, Collins SA, et al. European Respiratory Society guidelines for the diagnosis of primary ciliary dyskinesia. Eur Respir J 2017; 49: 1601090.

17 Munn Z, Peters MDJ, Stern C, et al. Systematic review or scoping review? Guidance for authors when choosing between a systematic or scoping review approach. BMC Med Res Methodol 2018; 18: 143.

18 Arksey H, O'Malley L. Scoping studies: towards a methodological framework. Int J Soc Res Methodol 2005; 8: 19-32.

19 Tricco AC, Lillie E, Zarin W, et al. PRISMA extension for scoping reviews (PRISMA-ScR): checklist and explanation. Ann Intern Med 2018; 169: 467-473.

20 Davis SD, Ferkol TW, Rosenfeld M, et al. Clinical features of childhood primary ciliary dyskinesia by genotype and ultrastructural phenotype. Am J Respir Crit Care Med 2015; 191: 316-324.

21 Davis SD, Rosenfeld M, Lee HS, et al. Primary ciliary dyskinesia: longitudinal study of lung disease by ultrastructure defect and genotype. Am J Respir Crit Care Med 2019; 199: 190-198.

22 Ellerman A, Bisgaard $\mathrm{H}$. Longitudinal study of lung function in a cohort of primary ciliary dyskinesia. Eur Respir J 1997; 10: 2376-2379.

23 Fuger M, Aupiais C, Thouvenin G, et al. Gas exchanges in children with cystic fibrosis or primary ciliary dyskinesia: a retrospective study. Respir Physiol Neurobiol 2018; 251: 1-7.

24 Gokdemir Y, Karadag-Saygi E, Erdem E, et al. Comparison of conventional pulmonary rehabilitation and high-frequency chest wall oscillation in primary ciliary dyskinesia. Pediatr Pulmonol 2014; 49: 611-616. 
Halbeisen FS, Goutaki M, Spycher BD, et al. Lung function in patients with primary ciliary dyskinesia: an iPCD Cohort study. Eur Respir J 2018; 52: 1801040.

Hellinckx J, Demedts M, De Boeck K. Primary ciliary dyskinesia: evolution of pulmonary function. Eur J Pediatr 1998; 157: 422-426.

Koh YY, Park Y, Jeong JH, et al. The effect of regular salbutamol on lung function and bronchial responsiveness in patients with primary ciliary dyskinesia. Chest 2000; 117: 427-433.

Lopes AJ, Camilo GB, de Menezes SL, et al. Impact of different etiologies of bronchiectasis on the pulmonary function tests. Clin Med Res 2015; 13: 12-19.

Maglione M, Montella S, Mirra V, et al. Long-term assessment of quality of life in primary ciliary dyskinesia: time for new tools? Chest 2014; 146: e232-e233.

Marthin JK, Petersen N, Skovgaard LT, et al. Lung function in patients with primary ciliary dyskinesia: a cross-sectional and 3-decade longitudinal study. Am J Respir Crit Care Med 2010; 181: 1262-1268.

Olveira C, Padilla A, Martínez-García MA, et al. Etiology of bronchiectasis in a cohort of 2047 patients. An analysis of the Spanish historical bronchiectasis registry. Arch Bronconeumol 2017; 53: 366-374.

Phillips GE, Thomas S, Heather S, et al. Airway response of children with primary ciliary dyskinesia to exercise and $\beta_{2}$-agonist challenge. Eur Respir J 1998; 11: 1389-1391.

Pifferi M, Bush A, Pioggia G, et al. Evaluation of pulmonary disease using static lung volumes in primary ciliary dyskinesia. Thorax 2012; 67: 993-999.

Shah A, Shoemark A, MacNeill SJ, et al. A longitudinal study characterising a large adult primary ciliary dyskinesia population. Eur Respir J 2016; 48: 441-450.

Sunther M, Bush A, Hogg C, et al. Recovery of baseline lung function after pulmonary exacerbation in children with primary ciliary dyskinesia. Pediatr Pulmonol 2016; 51: 1362-1366.

Tamalet A, Clement A, Roudot-Thoraval F, et al. Abnormal central complex is a marker of severity in the presence of partial ciliary defect. Pediatrics 2001; 108: E86.

Vallet C, Escudier E, Roudot-Thoraval F, et al. Primary ciliary dyskinesia presentation in 60 children according to ciliary ultrastructure. Eur J Pediatr 2013; 172: 1053-1060.

Videbaek K, Buchvald F, Holgersen MG, et al. The impact of mannose-binding lectin polymorphisms on lung function in primary ciliary dyskinesia. Pediatr Pulmonol 2019; 54: 1182-1189.

Ahmad F, Irving S, Alton E, et al. Multiple breath washouts in children can be shortened without compromising quality. Eur Respir J 2015; 46: 1814-1816.

Anagnostopoulou P, Kranz N, Wolfensberger J, et al. Comparison of different analysis algorithms to calculate multiple-breath washout outcomes. ERJ Open Res 2018; 4: 00021-02017.

Green K, Buchvald FF, Marthin JK, et al. Ventilation inhomogeneity in children with primary ciliary dyskinesia. Thorax 2012; 67: 49-53.

Green K, Ejlertsen JS, Madsen A, et al. Abbreviation modalities of nitrogen multiple-breath washout tests in school children with obstructed lung disease. Pediatr Pulmonol 2016; 51: 624-632.

Irving SJ, Ives A, Davies G, et al. Lung clearance index and high-resolution computed tomography scores in primary ciliary dyskinesia. Am J Respir Crit Care Med 2013; 188: 545-549.

Irving S, Carr S, Hogg C, et al. Lung clearance index (LCI) is stable in most primary ciliary dyskinesia (PCD) patients managed in a specialist centre: a pilot study. Lung 2017; 195: 441-443.

Irving S, Dixon M, Fassad MR, et al. Primary ciliary dyskinesia due to microtubular defects is associated with worse lung clearance index. Lung 2018; 196: 231-238.

Kobbernagel HE, Green K, Ring AM, et al. One-year evolution and variability in multiple-breath washout indices in children and young adults with primary ciliary dyskinesia. Eur Clin Respir J 2019; 6: 1591841.

Koucký V, Uhlík J, Hoňková L, et al. Ventilation inhomogeneity and bronchial basement membrane changes in chronic neutrophilic airway inflammation. Chest 2020; 157: 779-789.

Nyilas S, Schlegtendal A, Singer F, et al. Alternative inert gas washout outcomes in patients with primary ciliary dyskinesia. Eur Respir J 2017; 49: 1600466.

Nyilas S, Bauman G, Pusterla $\mathrm{O}$, et al. Structural and functional lung impairment in primary ciliary dyskinesia. Assessment with magnetic resonance imaging and multiple breath washout in comparison to spirometry. Ann Am Thorac Soc 2018; 15: 1434-1442.

Smith LJ, West N, Hughes D, et al. Imaging lung function abnormalities in primary ciliary dyskinesia using hyperpolarized gas ventilation MRI. Ann Am Thorac Soc 2018; 15: 1487-1490.

Cohen-Cymberknoh M, Simanovsky N, Hiller N, et al. Differences in disease expression between primary ciliary dyskinesia and cystic fibrosis with and without pancreatic insufficiency. Chest 2014; 145: 738-744.

Dettmer S, Ringshausen F, Vogel-Claussen J, et al. Computed tomography in adult patients with primary ciliary dyskinesia: typical imaging findings. PLoS One 2018; 13: e0191457.

Hoang-Thi TN, Revel MP, Burgel PR, et al. Automated computed tomographic scoring of lung disease in adults with primary ciliary dyskinesia. BMC Pulm Med 2018; 18: 194.

Jain K, Padley SP, Goldstraw EJ, et al. Primary ciliary dyskinesia in the paediatric population: range and severity of radiological findings in a cohort of patients receiving tertiary care. Clin Radiol 2007; 62: 986-993. 
Kennedy MP, Noone PG, Leigh MW, et al. High-resolution CT of patients with primary ciliary dyskinesia. AJR Am J Roentgenol 2007; 188: 1232-1238.

Li AM, Sonnappa S, Lex C, et al. Non-CF bronchiectasis: does knowing the aetiology lead to changes in management? Eur Respir J 2005; 26: 8-14.

Maglione M, Bush A, Montella S, et al. Progression of lung disease in primary ciliary dyskinesia: is spirometry less accurate than CT? Pediatr Pulmonol 2012; 47: 498-504.

Maglione M, Montella S, Mollica C, et al. Lung structure and function similarities between primary ciliary dyskinesia and mild cystic fibrosis: a pilot study. Ital J Pediatr 2017; 43: 34.

Magnin ML, Cros P, Beydon N, et al. Longitudinal lung function and structural changes in children with primary ciliary dyskinesia. Pediatr Pulmonol 2012; 47: 816-825.

Montella S, Santamaria F, Salvatore M, et al. Lung disease assessment in primary ciliary dyskinesia: a comparison between chest high-field magnetic resonance imaging and high-resolution computed tomography findings. Ital J Pediatr 2009; 35: 24.

Montella S, Santamaria F, Salvatore M, et al. Assessment of chest high-field magnetic resonance imaging in children and young adults with noncystic fibrosis chronic lung disease: comparison to high-resolution computed tomography and correlation with pulmonary function. Invest Radiol 2009; 44: 532-538.

Santamaria F, Montella S, Tiddens $\mathrm{H}$, et al. Structural and functional lung disease in primary ciliary dyskinesia. Chest 2008; 134: 351-357.

Tadd K, Morgan L, Rosenow T, et al. CF derived scoring systems do not fully describe the range of structural changes seen on CT scans in PCD. Pediatr Pulmonol 2019; 54: 471-477.

Alanin MC, Nielsen KG, von Buchwald C, et al. A longitudinal study of lung bacterial pathogens in patients with primary ciliary dyskinesia. Clin Microbiol Infect 2015; 21: 1093.

Cohen-Cymberknoh M, Weigert N, Gileles-Hillel A, et al. Clinical impact of Pseudomonas aeruginosa colonization in patients with primary ciliary dyskinesia. Respir Med 2017; 131: 241-246.

Roden L, Görlich D, Omran H, et al. A retrospective analysis of the pathogens in the airways of patients with primary ciliary dyskinesia. Respir Med 2019; 156: 69-77.

Rogers GB, Carroll MP, Zain NM, et al. Complexity, temporal stability, and clinical correlates of airway bacterial community composition in primary ciliary dyskinesia. J Clin Microbiol 2013; 51: 4029-4035.

Goutaki M, Halbeisen FS, Spycher BD, et al. Growth and nutritional status, and their association with lung function: a study from the international Primary Ciliary Dyskinesia Cohort. Eur Respir J 2017; 50: 4170659.

Svobodová T, Djakow J, Zemková D, et al. Impaired growth during childhood in patients with primary ciliary dyskinesia. Int J Endocrinol 2013; 2013: 731423.

Alanin MC, Aanaes K, Høiby N, et al. Sinus surgery can improve quality of life, lung infections, and lung function in patients with primary ciliary dyskinesia. Int Forum Allergy Rhinol 2017; 7: 240-247.

Behan L, Leigh MW, Dell SD, et al. Validation of a health-related quality of life instrument for primary ciliary dyskinesia (QOL-PCD). Thorax 2017; 72: 832-839.

Carotenuto M, Esposito M, Di Pasquale F, et al. Psychological, cognitive and maternal stress assessment in children with primary ciliary dyskinesia. World J Pediatr 2013; 9: 312-317.

Ioannou P, Kouis P, Kakkoura MG, et al. Health related quality of life in adult primary ciliary dyskinesia patients in Cyprus: development and validation of the Greek version of the QOL-PCD questionnaire. Health Qual Life Outcomes 2020; 18: 105.

Keniş Coşkun Ö, Gençer Atalay K, Erdem E, et al. Caregiver burden in children with cystic fibrosis and primary ciliary dyskinesia. Pediatr Pulmonol 2019; 54: 1936-1940.

Maglione M, Bush A, Nielsen KG, et al. Multicenter analysis of body mass index, lung function, and sputum microbiology in primary ciliary dyskinesia. Pediatr Pulmonol 2014; 49: 1243-1250.

McManus IC, Mitchison HM, Chung EM, et al. Primary ciliary dyskinesia (Siewert's/Kartagener's syndrome): respiratory symptoms and psycho-social impact. BMC Pulm Med 2003; 3: 4.

McManus IC, Stubbings GF, Martin N. Stigmatization, physical illness and mental health in primary ciliary dyskinesia. J Health Psychol 2006; 11: 467-482.

Pifferi M, Bush A, Di Cicco M, et al. Health-related quality of life and unmet needs in patients with primary ciliary dyskinesia. Eur Respir J 2010; 35: 787-794.

Valero-Moreno S, Castillo-Corullón S, Montoya-Castilla I, et al. Primary ciliary dyskinesia and psychological well-being in adolescence. PLoS One 2020; 15: e0227888.

Whalley S, McManus IC. Living with primary ciliary dyskinesia: a prospective qualitative study of knowledge sharing, symptom concealment, embarrassment, mistrust, and stigma. BMC Pulm Med 2006; 6: 25.

Zengin Akkus P, Gharibzadeh Hizal M, Ilter Bahadur E, et al. Developmental and behavioral problems in preschool-aged primary ciliary dyskinesia patients. Eur J Pediatr 2019; 178: 995-1003.

Cohen-Cymberknoh M, Atia O, Gileles-Hillel A, et al. Sleep disorders in patients with primary ciliary dyskinesia, cystic fibrosis with and without pancreatic insufficiency. Respir Med 2019; 151: 96-101.

Oktem S, Karadag B, Erdem E, et al. Sleep disordered breathing in patients with primary ciliary dyskinesia. Pediatr Pulmonol 2013; 48: 897-903. 
Santamaria F, Esposito M, Montella S, et al. Sleep disordered breathing and airway disease in primary ciliary dyskinesia. Respirology 2014; 19: 570-575.

Şişmanlar Eyüboğlu T, Aslan AT, Ceylan A, et al. Neurocognitive disorders and sleep in children with primary ciliary dyskinesia. Pediatr Pulmonol 2018; 53: 1436-1441.

Bush A, Payne D, Pike S, et al. Mucus properties in children with primary ciliary dyskinesia: comparison with cystic fibrosis. Chest 2006; 129: 118-123.

Cockx M, Gouwy M, Godding V, et al. Neutrophils from patients with primary ciliary dyskinesia display reduced chemotaxis to CXCR2 ligands. Front Immunol 2017; 8: 1126.

Cockx M, Gouwy M, Ruytinx P, et al. Monocytes from patients with primary ciliary dyskinesia show enhanced inflammatory properties and produce higher levels of pro-inflammatory cytokines. Sci Rep 2017; 7: 14657.

Paff T, Daniels JM, Weersink EJ, et al. A randomised controlled trial on the effect of inhaled hypertonic saline on quality of life in primary ciliary dyskinesia. Eur Respir J 2017; 49: 1601770.

Ratjen F, Waters V, Klingel M, et al. Changes in airway inflammation during pulmonary exacerbations in patients with cystic fibrosis and primary ciliary dyskinesia. Eur Respir J 2016; 47: 829-836.

Zihlif N, Paraskakis E, Tripoli C, et al. Markers of airway inflammation in primary ciliary dyskinesia studied using exhaled breath condensate. Pediatr Pulmonol 2006; 41: 509-514.

Kobbernagel HE, Buchvald FF, Haarman EG, et al. Efficacy and safety of azithromycin maintenance therapy in primary ciliary dyskinesia (BESTCILIA): a multicentre, double-blind, randomised, placebo-controlled phase 3 trial. Lancet Respir Med 2020; 8: 493-505.

Piatti G, De Santi MM, Farolfi A, et al. Exacerbations and Pseudomonas aeruginosa colonization are associated with altered lung structure and function in primary ciliary dyskinesia. BMC Pediatr 2020; 20: 158.

Loomba RS, Danduran M, Nielsen KG, et al. Cardiopulmonary exercise testing in fontan patients with and without isomerism (heterotaxy) as compared to patients with primary ciliary dyskinesia and subjects with structurally normal hearts. Pediatr Cardiol 2017; 38: 410-417.

Madsen A, Green K, Buchvald F, et al. Aerobic fitness in children and young adults with primary ciliary dyskinesia. PLoS One 2013; 8: e71409.

Ring AM, Buchvald FF, Holgersen MG, et al. Fitness and lung function in children with primary ciliary dyskinesia and cystic fibrosis. Respir Med 2018; 139: 79-85.

Simsek S, Inal-Ince D, Cakmak A, et al. Reduced anaerobic and aerobic performance in children with primary ciliary dyskinesia. Eur J Pediatr 2018; 177: 765-773.

Valerio G, Giallauria F, Montella S, et al. Cardiopulmonary assessment in primary ciliary dyskinesia. Eur J Clin Invest 2012; 42: 617-622.

Wells GD, Wilkes DL, Schneiderman JE, et al. Skeletal muscle metabolism in cystic fibrosis and primary ciliary dyskinesia. Pediatr Res 2011; 69: 40-45.

Joensen O, Paff T, Haarman EG, et al. Exhaled breath analysis using electronic nose in cystic fibrosis and primary ciliary dyskinesia patients with chronic pulmonary infections. PLoS One 2014; 9: e115584.

Kawakami M, Hattori Y, Nakamura S. Reflection of structural abnormality in the axoneme of respiratory cilia in the clinical features of immotile cilia syndrome. Intern Med 1996; 35: 617-623.

Kennedy MP, Noone PG, Carson J, et al. Calcium stone lithoptysis in primary ciliary dyskinesia. Respir Med 2007; 101: 76-83.

Marino LV, Harris A, Johnstone C, et al. Characterising the nutritional status of children with primary ciliary dyskinesia. Clin Nutr 2019; 38: 2127-2135.

Mirra V, Caffarelli C, Maglione M, et al. Hypovitaminosis D: a novel finding in primary ciliary dyskinesia. Ital J Pediatr 2015; 41: 14.

Montuschi P, Paris D, Montella S, et al. Nuclear magnetic resonance-based metabolomics discriminates primary ciliary dyskinesia from cystic fibrosis. Am J Respir Crit Care Med 2014; 190: 229-233.

Noone PG, Bennett WD, Regnis JA, et al. Effect of aerosolized uridine-5'-triphosphate on airway clearance with cough in patients with primary ciliary dyskinesia. Am J Respir Crit Care Med 1999; 160: 144-149.

Paff T, van der Schee MP, Daniels JM, et al. Exhaled molecular profiles in the assessment of cystic fibrosis and primary ciliary dyskinesia. J Cyst Fibros 2013; 12: 454-460.

Pifferi M, Bush A, Caramella D, et al. Matrix metalloproteinases and airway remodeling and function in primary ciliary dyskinesia. Respir Med 2017; 124: 49-56.

Shoemark A, Wilson R. Bronchial and peripheral airway nitric oxide in primary ciliary dyskinesia and bronchiectasis. Respir Med 2009; 103: 700-706.

Smit HJ, Schreurs AJ, Van den Bosch JM, et al. Is resection of bronchiectasis beneficial in patients with primary ciliary dyskinesia? Chest 1996; 109: 1541-1544.

Zihlif N, Paraskakis E, Lex C, et al. Correlation between cough frequency and airway inflammation in children with primary ciliary dyskinesia. Pediatr Pulmonol 2005; 39: 551-557.

Abitbul R, Amirav I, Blau H, et al. Primary ciliary dyskinesia in Israel: prevalence, clinical features, current diagnosis and management practices. Respir Med 2016; 119: 41-47. 
113 Boon M, Smits A, Cuppens $\mathrm{H}$, et al. Primary ciliary dyskinesia: critical evaluation of clinical symptoms and diagnosis in patients with normal and abnormal ultrastructure. Orphanet $J$ Rare Dis 2014; 9: 11.

114 Eden E, Choate R, Barker A, et al. The clinical features of bronchiectasis associated with alpha-1 antitrypsin deficiency, common variable immunodeficiency and primary ciliary dyskinesia - results from the U.S. Chronic Obstr Pulm Dis 2019; 6: 145-153.

115 Emiralioğlu N, Taşkıran EZ, Koşukcu C, et al. Genotype and phenotype evaluation of patients with primary ciliary dyskinesia: first results from Turkey. Pediatr Pulmonol 2020; 55: 383-393.

116 Frija-Masson J, Bassinet L, Honoré I, et al. Clinical characteristics, functional respiratory decline and follow-up in adult patients with primary ciliary dyskinesia. Thorax 2017; 72: 154-160.

117 Knowles MR, Ostrowski LE, Leigh MW, et al. Mutations in RSPH1 cause primary ciliary dyskinesia with a unique clinical and ciliary phenotype. Am J Respir Crit Care Med 2014; 189: 707-717.

118 Noone PG, Leigh MW, Sannuti A, et al. Primary ciliary dyskinesia: diagnostic and phenotypic features. Am J Respir Crit Care Med 2004; 169: 459-467.

119 Pifferi M, Bush A, Michelucci A, et al. Mannose-binding lectin 2 gene polymorphism and lung damage in primary ciliary dyskinesia. Pediatr Pulmonol 2015; 50: 179-186.

120 Yiallouros PK, Kouis P, Middleton N, et al. Clinical features of primary ciliary dyskinesia in Cyprus with emphasis on lobectomized patients. Respir Med 2015; 109: 347-356.

121 Goutaki M, Maurer E, Halbeisen FS, et al. The international primary ciliary dyskinesia cohort (iPCD Cohort): methods and first results. Eur Respir J 2017; 49: 1601181.

122 Miller MR, Hankinson J, Brusasco V, et al. Standardisation of spirometry. Eur Respir J 2005; 26: 319-338.

123 Quanjer PH, Stanojevic S, Cole TJ, et al. Multi-ethnic reference values for spirometry for the 3-95-year age range: the Global Lung Function 2012 equations. Eur Respir J 2012; 40: 1324-1343.

124 Chrispin AR, Norman AP. The systematic evaluation of the chest radiograph in cystic fibrosis. Pediatr Radiol 1974; 2: 101-105.

125 Brody AS, Kosorok MR, Li Z, et al. Reproducibility of a scoring system for computed tomography scanning in cystic fibrosis. J Thorac Imaging 2006; 21: 14-21.

126 Bhalla M, Turcios N, Aponte V, et al. Cystic fibrosis: scoring system with thin-section CT. Radiology 1991; 179: 783-788.

127 Helbich TH, Heinz-Peer G, Eichler I, et al. Cystic fibrosis: CT assessment of lung involvement in children and adults. Radiology 1999; 213: 537-544.

128 Dell SD, Leigh MW, Lucas JS, et al. Primary ciliary dyskinesia: first health-related quality-of-life measures for pediatric patients. Ann Am Thorac Soc 2016; 13: 1726-1735.

129 Lucas JS, Behan L, Dunn Galvin A, et al. A quality-of-life measure for adults with primary ciliary dyskinesia: QOL-PCD. Eur Respir J 2015; 46: 375-383.

130 Lucas JS, Gahleitner F, Amorim A, et al. Pulmonary exacerbations in patients with primary ciliary dyskinesia: an expert consensus definition for use in clinical trials. ERJ Open Res 2019; 5: 00147-2018.

131 Halbeisen FS, Jose A, de Jong C, et al. Spirometric indices in primary ciliary dyskinesia: systematic review and meta-analysis. ERJ Open Res 2019; 5: 00231-2018.

132 Halbeisen F, Hogg C, Alanin MC, et al. Proceedings of the 2nd BEAT-PCD conference and 3rd PCD training school: part 1. BMC Proc 2018; 12: Suppl 2, 1.

133 Farley H, Rubbo B, Bukowy-Bieryllo Z, et al. Proceedings of the 3rd BEAT-PCD conference and 4th PCD training school. BMC Proc 2018; 12: Suppl 16, 64.

134 Stanojevic S, Stocks J, Bountziouka V, et al. The impact of switching to the new global lung function initiative equations on spirometry results in the UK CF Registry. J Cyst Fibros 2014; 13: 319-327.

135 Robinson P, Morgan L. Bronchiectasis in PCD looks different to CF on CT scan. Multidiscip Respir Med 2018; 13: Suppl. 1, 24.

136 Campbell-Washburn AE, Ramasawmy R, Restivo MC, et al. Opportunities in interventional and diagnostic imaging by using high-performance low-field-strength MRI. Radiology 2019; 293: 384-393.

137 Edelman RR, Hatabu H, Tadamura E, et al. Noninvasive assessment of regional ventilation in the human lung using oxygen-enhanced magnetic resonance imaging. Nat Med 1996; 2: 1236-1239.

138 Werner C, Wallmeier J, Raidt J, et al. An international patient-registry for primary ciliary dyskinesia. Pediatr Pulmonol 2014; 49: S71-S72.

139 Goutaki M, Eich MO, Halbeisen FS, et al. The Swiss Primary Ciliary Dyskinesia registry: objectives, methods and first results. Swiss Med Wkly 2019; 149: w20004.

140 Goutaki M, Halbeisen FS, Kuehni CE. The time is right for an international PCD disease registry: insight and ongoing research activities. Eur Respir J 2017; 49: 1700357.

141 Rubbo B, Behan L, Dehlink E, et al. Proceedings of the COST action BM1407 inaugural conference BEAT-PCD: translational research in primary ciliary dyskinesia - bench, bedside, and population perspectives. BMC Proc 2016; 10: Suppl. 9, 66.

142 Gardner LE, Horton KL, Shoemark A, et al. Proceedings of the $4^{\text {th }}$ BEAT-PCD conference and $5^{\text {th }}$ PCD training school. BMC Proc 2020; 14: Suppl. 8, 7. 
143 Rubbo B, Lucas JS. Clinical care for primary ciliary dyskinesia: current challenges and future directions. Eur Respir Rev 2017; 26: 170023.

144 Amirav I, Roduta Roberts M, Mussaffi H, et al. Collecting clinical data in primary ciliary dyskinesia challenges and opportunities. F1000Res 2016; 5: 2031.

145 Goutaki M, Papon J-F, Boon M, et al. Standardised clinical data from patients with primary ciliary dyskinesia: FOLLOW-PCD. ERJ Open Res 2020; 6: 00237-2019.

146 Kuo W, Ciet P, Tiddens HA, et al. Monitoring cystic fibrosis lung disease by computed tomography. Radiation risk in perspective. Am J Respir Crit Care Med 2014; 189: 1328-1336.

147 Kubo T, Ohno Y, Kauczor HU, et al. Radiation dose reduction in chest CT - review of available options. Eur J Radiol 2014; 83: 1953-1961.

148 Behan L, Rubbo B, Lucas JS, et al. The patient's experience of primary ciliary dyskinesia: a systematic review. Qual Life Res 2017; 26: 2265-2285.

149 Emiralioğlu N, Karadağ B, Özçelik HU. Quality of life questionnaire for Turkish patients with primary ciliary dyskinesia. Turk Thorac J 2017; 18: 19-22.

150 Queiroz APL, Athanazio RA, Olm MAK, et al. Translation of the quality-of-life measure for adults with primary ciliary dyskinesia and its application in patients in Brazil. J Bras Pneumol 2019; 45: e20170358. 